\title{
The psychological costs of being different and ways of coping among sexual minority students in a South African University
}

\author{
Erhabor S. Idemudia ${ }^{1 a}$, Patricia Kolobe ${ }^{b}$ and Petunia Tsheole ${ }^{b}$ \\ a School of Research \& Postgraduate Studies (SoRPS), Faculty of the \\ Human \& Social Sciences (HSS), North-West University (Mafikeng \\ Campus), South Africa \\ ${ }^{b}$ Department of Psychology, School of Social Sciences, Faculty of the \\ Human \& Social Sciences (HSS), North-West University (Mafikeng \\ Campus), South Africa
}

\begin{abstract}
Homo-normative behaviour is socially not accepted in Africa and therefore such individuals are highly stigmatized. This places a burden on individuals who do not identify themselves as heterosexuals. Sexual minorities include homosexuals, bisexuals, trans-sexuals who suffer discrimination and victimization on campuses, so tend to falsify their self-identities. In the absence of a localized study among sexual minorities in South African universities, this study investigated whether sexual minority students in the university will report poor mental health, multiple identities and are able to reside in their environment. The study used a qualitative research design that allowed the researchers to dig deeper into the life experiences of the students from both individual and collective perspectives. Data was analysed thematically and feelings, values and meanings were connected through ideas and personal view points. Snowball sampling was used. The sample consisted of I I African students (four gays and seven lesbians) with ages ranging between 19 and 24 years. Participants were recruited from different faculties and levels of study. Two major themes were extracted during analysis and the principal outcome of the study was that homosexuals have a major challenge in their future work industry, have some identity crisis, poor psychological wellbeing and moderate resilience. The need to educate the public, university administrators and lecturers of sexual dynamics on campus amongst others were recommended.
\end{abstract}

Key words: Psychological wellbeing/Homosexuals/Resilience/Identity crisis/South Africa.

\footnotetext{
${ }^{1}$ Corresponding author: erhabor.idemudia@nwu.ac.za
} 


\section{Résumé}

Le comportement homo-normative (homosexuel) est socialement pas acceptée en Afrique et donc ces personnes sont fortement stigmatisées. Cela impose un fardeau sur les personnes qui ne se considèrent pas comme des hétérosexuels. Les minorités sexuelles comprennent les homosexuels, les bisexuels, transsexuels qui souffrent de discrimination et de la victimisation sur les campus et ont donc tendance à falsifier leurs auto-identités. En l'absence d'une étude localisée parmi les minorités sexuelles dans les universités sud-africaines, cette étude a examiné si les étudiants d'universités appartenant à des minorités sexuelles vont montrer des signes d'une mauvaise santé mentale, d'identités multiples et sont en mesure de vivre dans leur environnement. L'étude a utilisé un modèle de recherche qualitative qui a permis au chercheur d'accéder plus profondément dans les expériences de vie des étudiants sur deux points de vue individuels et collectifs. Les données ont été analysées par thèmes et des sentiments, des valeurs et des significations étaient reliées par des idées et des points de vue personnels. L'échantillonnage en boule de neige a été utilisé. L'échantillon se composait de I I étudiants africains (quatre gais et lesbiennes sept) avec des âges allant entre 19 et 24 ans. Les participants ont été recrutés dans différentes facultés et niveaux d'études. Deux grands thèmes ont été extraites lors de l'analyse et le résultat principal de l'étude était que les homosexuels ont un défi majeur dans leur future industrie de travail, avoir une certaine crise d'identité, bien-être psychologique et la résilience pauvres modérée. La nécessité d'éduquer les administrateurs et chargés de cours de dynamique sexuelle sur le campus universitaires publics, entre autres, ont été recommandés.

Mots clés: bien-être psychologique de crise ; homosexuels ; résilience

\section{Introduction}

Many societies in Africa are heteronormative. According to Perales (20I5), heteronormativity is a set of established cultural behaviour based on heterosexual relationships, and the legal and institutional system allows only for opposite sex romance or sexual relationships. Other forms of sexual behaviours are stigmatized leading to homonegative, homophobic (negative attitudes for homosexuals), bi-phobic (fearful attitudes for bi-sexuals) and transphobic (fearful attitudes for trans-sexuals) behaviours. The institution of marriage in Africa is defined and guided by heteronormative cultural values. These cultural norms frown and deride homosexuality because the act is against African culture (Matthew, Douglas \& Macdonalds, 20I2). According to Idemudia and Ndlovu (20I3), over $98 \%$ of marriages in Africa are between men and women and not between a man and man or woman and woman which is commonly defined as same-sex marriages.

Apart from being regarded as abnormal, homosexuality is stigmatized because it is 
associated with HIV/AIDS which further makes it immoral in the eyes of many Africans (Idemudia, 2010). Morality is central to African values (Idemudia, 2003, 2009). According to Dlamini (2006), homosexuality is seen to be culturally wrong in the African society and therefore should not be integrated in society. Many believe that the practice was not around until the arrival of the 'white person' and as a result, is seen as more of European phenomenon and therefore have been described as "white man's disease", (Smuth, 20lI). Studies (Balsom \& Mohr, 2007; Reed, 2013) have shown that homosexuals are often rejected, isolated, stigmatized and discriminated against, resulting in social exclusion even from their family members. Negative experiences of lesbian women and gay men are widespread in South Africa and collective gang rapes of lesbians are also very common.

According to Langhinrichsen-Rohling, Lamis and Malone (20I I), risk factors such as discrimination, stigma and rejection are strongly associated with homosexuality. These include possibility for greater isolation, lack of cultural access and family rejection. Homosexuals in South Africa have reported having experienced discrimination in public spaces such as taxi ranks, main roads, bus stops, parks and railway stations (Smuth, 20I I).

Being a confident disclosed gay man in a university or college society is extremely dangerous and difficult (Hall \& La France, 2007). Schmidt, Miles and Welsh (20II) noted that lesbian college students have reported experiences of harassment, fearing for their lives on campus, due to their sexual orientation. Such responses result in non-disclosures of gender identity. This feeling of fear may lead to poor psychological well-being in some cases (Schmidt, Miles \& Welsh, 20II; Baumann \& Muijen, 20/0). Being psychologically healthy in a university setting is important as it may affect academic performance.

Psychological well-being is viewed as the absence of any mental disorder and include components such as autonomy, self-acceptance, environmental mastery, personal growth, purpose in life and the ability to establish positive relations with others. It occurs when a person is satisfied with his or her life, is free from depression and feels hopeful and good about him or herself. Social isolation, on the other hand, can be defined as decreased interaction with other individuals. Research shows that social isolation can affect a person's psychological well-being and increase suicidal risk (Momtaz, Hamid, Ibrahim, Yahaya \& Chai, 20II). Traseen, Marntinussen, Vitterso and Saini (2009) asserted that depression among sexual minorities can be due to stigma or related to traumatic life events which could manifest as fear, depression and anxiety. According to Whitley (20I I), it is apparent that sexual minorities suffer higher rates of psychiatric disorders such as deliberate self-harm, substance abuse and suicide than their heterosexual peers. Common possible causal factors include stigma, social isolation, prejudice, discrimination due to cultural expectations. Using Australian data of LGBT, Perales (2015) confirmed that sexual identity no doubt influences a range of subjective wellbeing outcomes, including mental health, life satisfaction, psychological distress and feelings of safety and how its effect evolve 
over individuals' life courses and in addition, found that the subjective wellbeing of gay, lesbian and bisexual individuals is significantly worse than that of heterosexual individuals.

Within these cultural expectations, selfknowledge within cultural identity in Africa is very important and there is no self without others (Idemudia, 2009, Meyer, 2003). In this case, social pressures exist and young men are threatened to be disowned and forced to enter into marriage, in order not to violate gender roles and disrespect culture (Dlamini, 2006). In some African countries (Kenya, Uganda, Nigeria, Ghana, Senegal, The Gambia etc.), sexual minority is viewed as morally evil, seen as going against the African norms and traditions (Finerty, 2010) and anti-homosexual laws have been passed criminalizing same sex relations. As a result, many sexual minorities in university environments hide their identities. Robinson et al. (20l4) have implicated schools where most homophobic practices take place. Studies have shown that sexual minority students who hide their sexual identity may delay the development of a positive self-concept (Bos, Sandfort, Bruyn \& Hakvoort, 2008), which may in turn encourage discomfort with, or rejection of, their sexual identity. People who experience difficulty with internalized homophobia or low selfesteem often experience high levels of anxiety and depression (Bos et al., 2008). Gay and lesbian students have also been shown to possess multiple identities (Bowleg, Huang, Brooks, Black \& Burkholder, 2003; Bowleg et al., 2003; Graziano, 2004) due to experiences of discrimination and victimization. Sexual minorities have also been known to have poorer mental health, lower self-esteem, higher anxiety, depression, self-harm, suicidal ideation and suicidal attempts compared to heterosexuals (Perales, 2015; Uhrig, 2015; Institute of Medicine, 201I; King et al, 2007).

Anti-homosexual behaviours reduce disclosures and "cover up" which may have impact on the psychological wellbeing and resilience of homosexuals (Yoshino, 2006). The argument surrounding good indicators of psychological and social development when resilience is studied across different cultures and contexts (Broyden \& Mann, 2005; Castro \& Murray, 20 I0) is that young people and families may possess special skills that enable them to cope with discrimination and resist prejudice, however, sexual minorities show hidden resilience and do not conform to societal expectations on how to behave (APA, 2008; Ungar, 2004).

The social identity (Ellemrs, Spears \& Doosje, 2002) argues that different social contexts can lead to the silencing of group membership. Group members will then be encouraged to protect their self-worth and accomplish optimistic, but different social identity and once the social identity becomes significant, intergroup differences may emerge again giving rise to intergroup discrimination. Individuals in a group might categorize or be categorized by what is called in-group bias. For example, when homosexuals are challenged, they can withdraw or isolate themselves in a group or behave in a specific manner in order to fit in a group, which might enable the homosexual individual to develop multiple identities (Miles \& Kivlighan, 20I2). The person might end up being a heterosexual 
in some contexts or environment and a homosexual in other contexts which may end up affecting the psychological wellbeing of such individual because of not being who they want to be and hence identity crisis as stated by Cass (1979) model of identity formation. However, mental health issues emerge when gay and lesbians internalize or try to act against or disprove stereotypes of sexuality and sexual orientation. In fact, some women expend much psychological and emotional energy trying to dispel stereotypes or to appear "normal" within a society that pathologizes lesbian identities (Greene, 2000). While some try to bring effective adaptive strategies to managing their multiple identities (Gibson, Schlosser \& Brock- Murray, 2007), it has been noted that lesbians have a greater likelihood of experiencing loneliness, social isolation and tension, but are less likely to seek professional help (Mays \& Cochran, 2000). Research findings suggest that lesbians may be more vulnerable to the effects of chronic stressors and may experience an elevated rate of negative psychological outcomes by the time professional help is finally sought.

Research indicates that being a homosexual individual is compatible with healthy mental health and social adjustment. However, rejections and discriminations by family and friends and others, signify that several sexual minority students could experience mental health and substance misuse problems greater than expected (King et al., 2003; Gilman, Cocharn, Mays, Hughest, Ostrow \& Kessler, 200I) and in addition aggravate the nature of multiple identities among sexual minority in universities (Rhoads,
1997). Resilience refers to an individual's capacity to cope with stress and adversity. A study in Ireland has shown homosexual individuals to be happy people than unhappy in comparison to other studies (Mayock, Bryan, Carr \& Kitching, 2009). On psychological wellbeing, Ryff (1989) developed the concept of interpersonal flourish which according to Compton (2005) refers to the positive relationship that people have with others which help facilitate elements of psychological wellbeing. Ryff proposed a six dimensional model of psychological well-being: autonomy, environmental mastery, personal growth, positive relations with others, purpose in life and self-acceptance (Ryff, 1989). Failure to overcome many of these elements will affect wellbeing. Proponents of minority stress theory (Herek \& Ganets, 2007) have tried to explain how homophobic behaviours such as stigmatization and discrimination affect the subjective wellbeing of sexual minorities. Rostosky, Riggle, Gray and Hatton (2007) defined minority stress as chronic social stress because of membership to a stigmatized group.

Unfortunately, many of the studies reviewed above were either narrative in approach (Dlamini, 2006, Idemudia, 2010) or the studies were carried out in nonAfrican settings therefore creating knowledge gaps. To bridge this gap, this study therefore, is designed from a qualitative approach to investigate whether sexual minority students in the university will report any identity crisis, poor psychological wellbeing and are able to resile in their environment. Sexual minority students are defined as those who selfidentify as gay, lesbian, or bisexual or those 
who are involved in sexual relations with people of the same or both sexes.

\section{Methodology}

\section{Design:}

The study used a qualitative research design which according to Creswell (2007) helps to discover meanings and feelings attached to experiences which are both individual and collective narrations.

\section{Setting and Participants:}

The research was conducted with students from the North-West University (Mafikeng Campus) in the North-West Province of South Africa. These were undergraduate and postgraduate students from different cultural groups of South Africa with age ranging from 19-25 years. Due to the nature of the sensitivity of the study and because participants were a hard to reach group, the students were sampled using snowballing method from different faculties and levels of study. Snowball sampling is a technique for finding research subjects using another subject whereby the researcher accesses participants through contact information provided by other informants (McLean \& Campbell, 2003, Noy, 2008). In this study, the researchers identified and contacted one respondent purposefully, after which the first participant referred the researchers to the second participant who later referred them to another participant, and so on, until the sample size of II participants was reached which were four gays and seven lesbians. The inclusion sampling criteria were that the participants must be gay, lesbians, bi-sexual or transsexuals and must be bonafide registered students of the university during the time of data collection. Exclusion criteria include selfidentified heterosexuals and unregistered students.

\section{Procedure:}

Data was collected in English since participants were multicultural and later transcribed and checked by a qualitative researcher. Permission to conduct the research was obtained from the ethical committee of the North-West University (Mafikeng Campus). The participants were initially contacted individually and then as a group having arranged a convenient time and date. The aim of the study was communicated clearly to the group after they had given their written consent to participate in the study. The participants were also assured that their identities would be protected and the information they provide will be treated with confidentiality. They were also made aware that their participation was optional and they have the right to withdraw from the research at any time during the process without penalization. No monetary incentives were offered to participants. The researcher ensured that the questions were written in Grade 4 English and understandable to the participants. Anonymity was assured during the interviews.

Table I shows a summary of the characteristics of the participants in the study. 
African Population Studies Vol. 29, No. 2, Supplement, 2015

Table I. Demographic information of Participants

\begin{tabular}{|c|c|c|c|c|c|c|c|c|c|c|c|}
\hline Participant & I & 2 & 3 & 4 & 5 & 6 & 7 & 8 & 9 & 10 & 11 \\
\hline Age (years) & 19 & 23 & 23 & 20 & 22 & 21 & 24 & 24 & 24 & 23 & 25 \\
\hline Gender & $\mathrm{F}$ & $\mathrm{F}$ & $\mathrm{F}$ & $\mathrm{F}$ & $\mathrm{F}$ & $M$ & $\mathrm{~F}$ & $M$ & $M$ & $\mathrm{~F}$ & $M$ \\
\hline Level /Year of study & $I^{\text {st }}$ & $I^{\text {st }}$ & $4^{\text {th }}$ & $I^{\text {st }}$ & $2^{\text {nd }}$ & $2^{\text {nd }}$ & $4^{\text {th }}$ & $I^{\text {st }}$ & $2^{\text {nd }}$ & $3^{\text {rd }}$ & $4^{\text {th }}$ \\
\hline Academic Specialization & 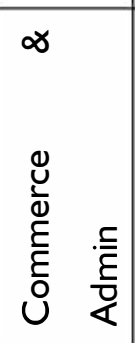 & 忌 & 忌 & 矛 & 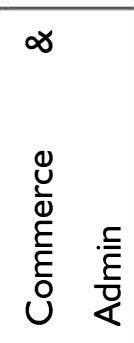 & 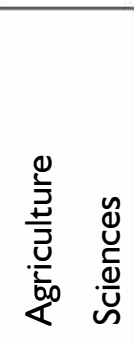 & 忌 & 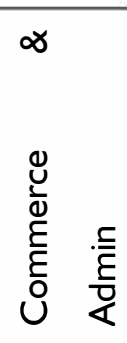 & 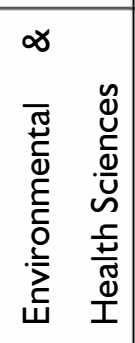 & 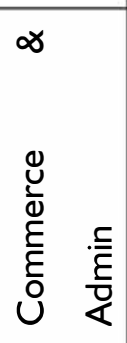 & 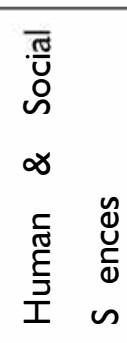 \\
\hline Culture & $\frac{\overrightarrow{2}}{\vec{N}}$ & 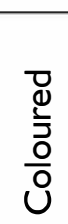 & $\frac{\vec{J}}{\vec{N}}$ & 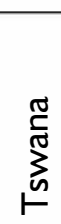 & 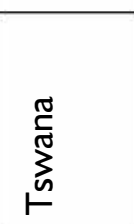 & 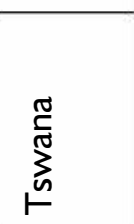 & 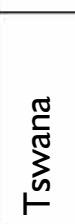 & 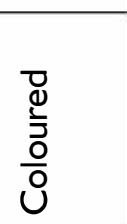 & $\begin{array}{l}\tilde{g} \\
\stackrel{0}{0} \\
\stackrel{+}{x}\end{array}$ & 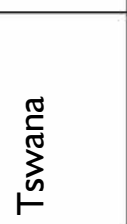 & $\frac{\overrightarrow{2}}{\vec{N}}$ \\
\hline
\end{tabular}




\section{Method for data capturing:}

One focus group interview was conducted for both lesbian and gay participants. The following questions were asked: How did you realize that you were gay or lesbian? What are your feelings around this? What are your experiences with your culture of homosexuals and within the university culture? Member checking technique was used throughout the group discussions to establish the validity of a given interpretation. In this technique the researchers were allowed the opportunity to understand the participant's explanations by giving other participants some opportunity to correct errors and challenge what they perceived as incorrect interpretations. Other participants volunteered to give additional information which might be stimulated by the playing back process of questioning, providing the researchers with an opportunity to summarize the preliminary findings and results as well as confirming particular aspects of the data (Angen, 2000). The technique also gave each member the opportunity to give a wider variety of responses and explanations of their experiences. Field notes were taken during the interview to document and interpret the unstructured observations, emotions, perceptions and prejudices made in the field (Polit \& Beck, 20l0). This provided the researcher with an opportunity to clarify complex issues that might have been controversial or personal.

\section{Data analysis}

Thematic analysis was used to analyze the data. Feelings, values and meanings were connected through ideas and personal view points. The approach also allows collected data to be analyzed, patterns are identified and reported as themes (Maree, 2007) using the prescribed procedure. Textual data were obtained as a result of the method used. Data was transcribed and coded, organized into file folders and index cards. The research adopted a three dimensional space approach and narratively analyzed data in three elements: interaction (personal and social), continuity (which is the past, present, future), and situation (physical places or the storyteller's places) (Clandinin \& Connelly, 2000). Thematic analysis was then used to yield knowledge and new insights into key ideas and themes that give answers to the research questions (Braun $\&$ Clarke 2006). The researchers used a combination of multiple data collection to ensure the trustworthiness of the findings. Findings from individual, narratives, filed notes and member checking techniques were integrated and thereafter elaborated on the story in an interlinking manner.

\section{Results:}

The findings exemplify some elements of confusion, frustration and fear for the future with some indicators of the sexuality minority community as a source of their resilience. Two dominant themes emerged during analysis. Theme one is; Experiences of the homosexuals embedded from three sub-themes which are: identity crisis; fear for future rejection as a future professional; and psychological stress. Theme two illustrates indicators of resilience with selfacceptance; sexual minority community and identity tolerance as sub-themes.

Experiences of the homosexuals 
Identity crisis and personal feelings associated with sexual identity crisis. Some common feelings were revealed around the participants' personal experiences of sexuality. The fact that it is not their choice to be homosexuals has led to different feelings which, centres on lack of self acceptance. Almost all the participants indicated that it was not their choice to become homosexual. The literature does not state clearly that all the participants do not choose to be homosexual. According to the participants they would be straight if they were given the choice that is they would be heterosexual individuals. Some indicated that they even pray to God about their homosexuality because they do not like it:

It's not a choice... Yeah if sexuality was a choice, I would not be lesbian (yes... yes... [Others agreed in and emphasizing way] [Participant \#2].

Other participants agreed and added, [Participant \# I]: If I had a choice, I would be straight because why choose to be something that people are going to see as being deviant from society... it is painful. [Participant \#6]: It's not... (With some pain in the voice) it's not a choice. Why wake up in the morning and feel like-oh my gosh, I want to be so gay today?

[Participant \#4]: You know you might get killed, you might get raped .....how can you choose it? Yeah? It is like when I'm born, when I grow up I find myself being black and not white. Did I ever choose it or it chose me? It's not your choice! (emphasizing the point).
[Participant \#9]: Even after realizing I was gay, I did not accept myself; I did not want to be gay... I did not like it at all (emphasizing the point hard) that's why we say it is not a choice."

[Participant \# 7]: It is not... a... choice, not at all! People think you just wake up one day and say I want to be lesbian. It's not! It just hurts! [Feelings of hurt on the face]. Yeah I despised it, it made me cry, I did not like it... I despised it... (Pauses and voice trembling) I didn't even want to think about it or see anything about it... I hated it... I hated other girls because I did not want to love them. [Participant \#6].

[Participant 6]: When I realized that I'm "Sque" (not straight)... I did not want to be called gay at all...not at all....by anyone...

[Participant \#2] If I understood why I'm homosexual, I could not have prayed to God... I have prayed, used anointing oils asking God to change me, it didn't work because here I am, I am still gay... I'm still gay.

[Participant \# I: I prayed, I fasted, you know what, I tried everything saying please God change me because I wanted to be out of this mess, it did not work.

[Participant \# I0] I also went through that route... I was confused and praying... I was praying hard.

[Participant \# I]: With me I prayed all the time... I would go to church and pray. The participants expressed a range of negative feelings describing their sexuality as painful, confusing, depressing, and 
abnormal. Some experience their sexual status as painful:

[Participant \# 10]: One statement that really pains me all the time is what my brother once said to me, he said [Peggy, (not Real name) may you please stop depriving me of having a little sister, I have a sister not a brother...] It is painful to hear your brother begging you like that mostly when you are the only sister like me...

It's painful... (Long pause, a big sigh and trembling voice) very painful, it's confusing and depressing. Yes... that is why some end up killing themselves [Participant \#7]. Some regard their sexuality as abnormal:

[Participant 6]: Yeah...it is something which is very abnormal. Yes... It's not right because even the way we have been raised up, it does not agree with it.

Some participants reported feelings of embarrassment and shame, especially when they are with people they respected. One of the gay participants stated:

[Participant \#9]: Once somebody said 'hi, girl' to me in front of my grandmother, I felt so embarrassed and very ashamed because I never want my grandmother to believe I am gay, never.

To some, the feeling is frustrating and very stressful:

[Participant \# I I]: This thing frustrates me like I am not able to accept myself while with other people, I am always in the company of straight people and when I am with them, I don't feel any comfort because I feel very different from them... it is very stressful.
[Participant \# 10]: I am always stressing because of this issue.

The fact that the participants did not like or accept their sexuality has led to experiences of feelings of inner turmoil and personal alienation. According to the theory of Cass (1979), cited by Meyer et al. (2007), this indicates that the participants experience identity confusion which later leads to identity crisis and poor psychological well-being.

\section{Fear of rejection by the society}

In numerous cases some have been judged negatively:

[Participant \#9]: Something is wrong, very wrong about this one...

Some would even be told they are not human beings:

People will be telling you that you don't have a soul... you're lost! You should change now you are not a human being because of what you do. It builds up to a certain point where it creates a scar, a permanent scar on the person. [Participant \#7].

Sexual minorities are regarded as a disgrace by society. [Participant \#7]: Talking about things such as homosexuality, and being that, is a disgrace to the society, (others agree) it is like a spit on the face.

They get very negative comments from the society: 
[Participant \#4]: Why don't you take this rubbish and lock it up... They need to be locked up, and beaten the hell out of their heads and this thing will come out.

Some participants feel they have brought shame to their families because of the way people see them:

[Participant \#3]: I was raised according to the Bible, so it was like where you are going Patience? (Not her real name) More especially at home they chase you away because you are a disgrace to them..., and have brought shame to their family.

The participants have experienced a loss of their uniqueness and identity, respect and friendship due to their sexuality:

[Participant \#8]: It is more difficult because, you lose everything as a guy. You lose respect; you lose your status, especially more so when you are "top". If you are the dominant guy, you lose so many things. You lose your friends because none of them would want to be your friends anymore.

[Participant \#6]: Because it's a stigma, we lose our dignity. It's a stigma. If you're lesbian, you're up for every girl, yeah... and if you are a guy, you are after every guy. So even if you say "hello" to a guy, according to the campus society and that individual, you want him... I've realised with guys that they are really hated... painfully... and more than us girls." [Participant \# I0].

The results agree with the findings of some other studies that participants never revealed their status as people belonging to the social group in order to avoid loneliness (Ellerns et al., 2002).

Rejection by other students is also one of the participants' experiences. Some of the participants' straight friends would try to convince them at first and thereafter reject them if they refused to change their sexuality. According to the participants, life on campus is sometimes unsafe for lesbian students who experience harassment from male students. Most of them reported experiences of feeling being disrespected at times because of their sexuality.

There was a party on campus, I went to the ladies and I was alone, I don't know if that guy followed me or what, when I looked on top of the wall there, he is peeping at me from the other toilet from the top. Imagine, in a female toilet, I don't even know what he wanted to see... maybe to check if I am a real girl, I mean that is totally wrong... I was not secure because it was late at night. [Participant \#3].

Many come across situations whereby men get jealous of their girlfriends socialising with their lesbian peers, attributing this to the male students' insecurity. Hall and La France (2007) emphasised that being a homosexual student in a university society is extremely painful and dangerous. Schmidt, Miles and Welsh (20II) also affirmed that lesbian students at times experience harassment on campus. In some instances, some female participants reported that they experienced sexual violence from fellow students:

Some of the male students pretend to be friends and even pretend they support 
and understand us, giving you one drink after the other so that you become drunk and then they start harassing you. Most of those kinds of males end up raping lesbians just to remind them that they are girls and not boys [Participant \# I0].

More studies have confirmed that sexual minorities have complained about their safety in universities and that they felt that hiding their sexuality is always the best thing to do to avoid intimidation, harassment and insecurity (Schmidt, Miles \& Welsh, 20II).

You never really know when to conduct your real self in case you go beyond those boundaries. There is an easy influence against homosexuality around the campus. You cannot say somebody is a friend or not because they just change any time. As soon as the third party comes into picture, they get easily influenced and embarrass you and reject you. [Participant \#4].

The results therefore lead to the fact that homosexual students experience some stress, while on campus because of fear of harassment, thus placing them at risk of poor psychological wellbeing.

Discrimination as students: The participants in this study reported experiencing discrimination around campus leading to pain, it was already hard enough for them being homosexual on campus, and it was still going to be hard enough for them in their chosen professions. The findings have also revealed that people around these lesbians and gay people would just offend them, and instead of the higher authority intervening, they rather agreed with the discrimination. The results have also shown that these university minority groups of homosexual students experience hardships and discrimination that makes it difficult for them to manage their environment that is, environmental mastery is a challenge to them and they have not achieved it. The participants revealed experiences of discrimination around the campus on different occasions.

We are being discriminated, at times, being bad mouthed, being told this and that ....that you simply walk away and never respond to all these painful remarks. [Participant \#3].

Some have felt despised by others,

..... when we told this lady to give us a venue and told her that the seminar was about, that it was for homosexual international day and against homophobia. She asked us, "Oh, it's for homosexuals?" So we were like... yes. And then she continued by saying, "Oh. Are you guys going to be cross dressing and start behaving funny?" and we are like, huh? Are we acting like people of the opposite sex? She said, "yes you are barbaric, you are going to wear your things." And we were all like, what! [Participant \#7].

... it's like they do not have a clue of how the gays and lesbians live... they would say I know that you are a lesbian and you use drugs. We are associated with drugs, which is why we live on drugs and alcohol. [Participant \#4].

With some of the participants, the discrimination comes from some lecturers:

... we were dealing with a case of sexuality - I am a law student. She gave an 
example and said, "Imagine you're a lesbian, representing someone in court. What will people think about you?" [Participant \# 7].

On the other hand some say that:

Sex-talk is everywhere, on television, it is everywhere, but what people fail to understand is that not only heterosexuals are at risk, we are also at risk of contracting diseases, which means that we need the sex-talk as well at least on campus during the love life campaigns, they never cater for us, all I see is heterosexual condoms, what about our condoms, What about our condoms? We are being discriminated against (stressing the point). We've got our specialized condoms, but they are in no clinic! [Participant \#2].

Fear of rejection as a future professional. The participants felt that even after they had finished school, the work industry would still be a real challenge to them because of their sexuality. Cole and Guy-Sheftall (2003) stated that even people in higher positions for example lecturers, have their way of embarrassing and saying things in public that offend and humiliate the homosexuals leaving them with painful self-judgment of being gay or lesbian. One participant remarked:

I'm a law student, and the thing is, I want to be an attorney. But, what I'm afraid of is my sexuality around that (workplace) because I wish to see myself wearing suits, men' suits! (Lesbian). And I don't think it will be allowed [Participant \#3].
[Participant \#2]: Imagine you're going to court wearing man' suit and you are a woman, is the judge going to take you seriously?

[Participant \#7]: Even the people in court... what will they think of you?

[Participant \#4]: With me, the worst thing is I want to be a prosecutor, so you can imagine, I'm going to stand at the high court and represent the state, not only an individual but the state, are they going to allow me go to court being myself, wearing men' suit?

The participants also feared that they would not progress in the working industry because of their sexual status.

[Participant \#7]: The thing is, even if I can pass my masters with distinctions, am I going to be promoted like any other person who is not homosexual? I will be stuck in one position for the rest of my life. I won't be respected, because I'm lesbian. This is also challenging in our careers and everything that's why l'm saying being out is a risk that you are taking, you want to accept yourself and it's not easy... you look at yourself, your family, your future, your whole life! It is all a mess. How do you go out to reveal your sexuality? For you to be a failure in life, it's painful.

[Participant \#PI0]: I don't want to be homosexual. Who is going to hire you? You can have your masters, you can be the best, but the fact that you are homosexual and you are proud about it, you are not even willing to change for the company. You will never progress. Imagine the way 
corruption is in our country already and think of how it will be now that you are a lesbian?

Another concluded:

[Participant \#4]: Last time I was talking to Susan (not her real name), saying that I want to be the best accountant and end up a financial whatever, but I have made up my mind that I will live a double identity kind of life, when I go to work, I will wear dresses, skirts, nice lady suits and high heeled shoes because I want to go far with my career.

According to Compton (2005), if the participants' needs are not satisfied, they are not able to control their lives, and they feel they do not fit in within the campus environment and work industry. In this case, according to Ryff's (1989) theory of psychological wellbeing, the individual's failure to master their environment is one of the indicators of poor psychologicalwellbeing, which is the case with the participants in this study as they are not able to cope and fit into their environment. The finding also supports the minority stress theory (Herek \& Ganets, 2007) which tried to explain how homophobic behaviours such as stigmatization and discrimination affect the subjective wellbeing of sexual minorities.

\section{Multiple Identities.}

The participants believe that culture also plays another role in making them display different identities when they are around members of their communities in order to be accepted. Due to discrimination experiences and harassment on campus, sexual minority students decide to display multiple identities depending on where they are and who they are with. According to some studies, the experience of discrimination from society indicates that while most homosexuals want their families and churches to be their support systems, gays experience a multitude of challenges from these, leading to multiple social identities (Herndon \& and Hirt, 2004; Jones \& McEwen, 2000; Stewart, 2000), reflecting problems of identity crisis. The results are also in agreement with Yoshino (2006) that homosexuals try to minimize stigmatization towards their sexuality by not coming out in the open unless they feel it is safe for them to do so. The problem of multiple identities does not only reveal itself through clothing and resemblance, but also through the participants not disclosing to the family and in order to keep the identity of their sexuality a secret in the family, the identity they reveal at home is not the one they reveal when they are out on campus with their friends.

I don't tell my grandfather, I would never! I feel that immediately I tell my grandfather that this is what is going on with me I will kill him [Participant \#7].

Another one added:

With my grandmother, even though she does not know about my sexuality, since she raised me up in a Christian way, every day when I arrive she opens the Bible to me and start teaching me how to behave, my best friend is a super bitch and I grew as a tomboy so it is like, "Lorraine (not her real name), do not be like this girl." What if I tell her, she will drop dead. I will never reveal my sexually identity to her, not if she is still alive. She even packs my church 
uniform for me when I leave for school [Participant \# 10].

Patton and Simmons (2008) affirm that sexual minorities in universities have multiple identities. Robinson et al (20/4) claims homophobic behaviours are common with teachers and fellow students. Despite the fact that most lesbians dress the way they like and show their masculine bodies, when they get home, they wear feminine clothing. They are aware of their personal self-images, yet also aware of the pain they will cause once their families come to know the truth of their sexuality (Blumer, 1969; Brown, 2006).

In most cases, the participants display multiple identities because they feel they will not be safe in some places indicating that one has identity crisis.

We were walking past these two men and my girlfriend said, "... and you know baby” I said, Hey! Watch out. Don't call me baby in public. It's not a matter of being shy, but it is for security. There is a lot of harassment and killing and everything out there for homosexuals. It is risky. [Participant \#6].

The other participant said, "I feel this place is much safer than other places. Where I come from, I cannot just walk freely, they will kill me' (emphasizing the killing) [Participant \# I0].

Other participants added:

... Most lesbian killings and rapes are out there [Participant \#4].

The issue of lesbians and gay people's identity crisis is known everywhere. Two major reasons for their disguise are to feel safe in their community as well as to show respect to their community and their culture as people. This is affirmed by Bridges, Selvidge and Matthews (2003), that homosexuals are seen as incongruent to the expectations of what people should behave and thus they can be beaten up or even raped and killed in some places to teach them to respect their culture.

Psychologically, the theory maintains that incongruence generates psychological tension; individuals who seek to achieve congruence affect their cognitive thinking and end up displaying behaviours of stress since incongruity generates psychological tension and stress (Devos \& Banaji, 2003). Some studies also agree with the fact that theoretically, adolescents are at the stage of critically trying to identify who they are, that is, the university students are in their late adolescence stage whereby they are in the process of establishing the choices they have made about themselves. It is therefore during this process that the adolescents become keenly aware and sensitive to their external presentation to their families and community, and consequently to other people's perceptions (Casey, Tottenham, Liston \& Durston, 2005; Jamil, 2010) As a result, during this stage, they gradually develop a greater understanding of their identity and the tension it causes due to lack of acceptance by their community (Brown, 2006). It is through the process of internal hypothetical thinking, among other cognitive changes in the adolescence, that the homosexual adolescents begin to question and have a deeper understanding of who they are. The homosexuals in this case experience lack of self-acceptance 
and environmental mastery, leading to poor psychological well-being.

\section{Psychological stress}

The highlighted feelings stated earlier as those that result from all the experiences of being homosexual have led to some chronic stressors that leave the individuals with negative thoughts about their lives and risky behaviour including thoughts of suicide. The findings of this study about abuse of alcohol, drugs and sexual addiction are asserted by other researchers. Perales (2015) claims that sexual identity certainly influences a range of subjective wellbeing with sexual minorities; reporting their poorer state of mental health than heterosexuals. According to King et al. (2003) and Gilman et al. (200I), all the stress and the pains caused by societal discrimination, rejection and identity confusion mean that some sexual minority students experience a greater than expected prevalence of psychological health problems. Therefore, according to the participants, to ease this psychological stress, drugs and sex become the common de-stressors (LanghinrichsenRohling, 20II).

\section{Self-medicating (Females).}

It has been emphasized from this study that substance misuse and sexual dependence are common practices among homosexual students because of the stressors faced by them. Almost all the participants have gone or are still going through one of the problems.

You don't know the reason behind some of the abuse of alcohol and drugs. (response from all the participants - yes) I was one of those people. I used to drink myself to death (yes) because... (Laughing) because I didn't accept who I am since I was telling myself that it was wrong... no it is wrong to be attracted to another woman... I'm not lesbian, I'm not... [Participant \#4].

One participant emphasized that:

I think where the misconception lies are that we are lesbians because we turned to drugs... It's actually because we are lesbians that it is too much to deal with (all participants agreed by saying yes), then we resort to drugs to try to balance the stress [Participant \#3].

\section{One added:}

It's not just to accept who we are, yeah, psychologically we are not well at all because of the mixed feelings, so confused, so hurt, so everything. The truth to me is, when you drink or use drugs, it starts healing, it's like you stabilize [somebody intervened] it's like when you say you are in pain, when you drunk, you don't feel that pain at that time... [Participant \#5].

We use drugs due to some kind of psychological pressure. [Participant \# I0].

Sexual needs/Abuse (Males).

The findings specified that, in most cases, the lesbian participants turned to drugs and alcohol, while the gay participants used sex. One gay participant highlighted:

...but then gay people are different, because we have sex addicts, that's what most of the people will tell (you), that gay people are sex addicts. They love sex only, you know... Because as men, naturally we are sex animals... so whatever the pressure 
we are feeling, we project it to sex... [Participant \#8].

...if they think they are happy, its sex... that's why if you can check, the issue of sex partners is really dominant with gay people. That is, no, we are not dating; he is just my sex partner... why can't you just date him... Because sex is our de-stressor, we are addicted to it, okay fine, we drink, but then sex is like the ultimate one (hmmm) and it's not like girls... girls drink [Participant \# I].

\section{Suicide.}

The participants indicated that they also experience situations whereby some of them end up with suicidal thoughts and attempts to commit suicide. One participant commented:

...that's why others end up killing themselves, it's because they don't know how to handle themselves and it becomes too heavy for them, it's the family this side, the society say this, the friends also say their own things that side, you end up being so confused and you hate yourself. What will you do? So the only way for you is to just rest... is to just take your life" [Participant 3].

Another added, "... it is so depressing... yes, that's why some of them end up killing themselves... [Participant \#7].

The findings have revealed that the homosexual students experience a lot of stress that leads to a high rate of substance use and sex addiction, which may later lead to suicide with some, aligning with other studies (Bowleg et al., 2004; Lock \& Steiner, 1999; Mays \& Cochran, 2000).
With reference to Ryff's (1989) theory of psychological wellbeing, the participants would have a desire to be somebody in society (Meyer, 2003) and thus they continuously go through some stress and depression because of trying to live a life approved by society, whilst at the same time doing what their society rejects. In this case, their self determination to be part of society brings confusion and stress which are indicators of psychological wellbeing.

Furthermore, the findings have shown that there are challenges to personal growth with most of the participants since they continuously move back and forth due to these challenges they experience in society. The participants feel if they try to make use of their talents and capabilities in society, they are restricted by the issue of their uniqueness as a sexual minority group.

Further, the participants seem unable to have steady relationships with others who are not within their sexual minority group, since they want to avoid discrimination and betrayal. By applying Ryff's (1989) theory, the findings also reveal that the majority of the participants do not experience self-acceptance. When they evaluate themselves, they are unable to accept themselves due to the fact that the environment around them is rejecting their uniqueness. In this case they have displayed an element of self-rejection and negativity towards the self.

\section{Resilience}

Resilience is the ability to flourish and to self-accept in the face of adversities. Participants in this study showed how to resile by self-accepting themselves. 
Self-Acceptance. Although it may still be hard for them, at least a few of the participants have accepted who they are.

I was there... that's why I say I'm happier here... I'm happier than that because I was trying so hard, yeah, so hard to be something that's not me, I feel like a survivor, a warrior. Although I just went to a next stage it's still not easy because I now just have to fight a bigger demon of opposition but I feel strong. [Participant \#7].

Another one added:

You beat me up, you rape me, you know what, and it's not going to change me! (Beating the table) when I wake up I am still the same lesbian you have tortured. [Participant \#3].

Sexual minority community.

The findings have shown that some, although very few, individual homosexual students are able to cope due to the support they get from their minority group.

One of the participants stated that after going to a tertiary school in Rustenburg, found out that these things are there when I came to the university that's when I came to the reality that I am gay. I feel a bit comfortable and I am accepting it because this group (pointing at the participants, are always trying to help me. [Participant \#9].

Another stated, I will rather say because you see a lot of people who are like you, then we say it is a build-up to what you thought you are, exactly unlike when they are all straight. [Participant \#6].

Some studies have asserted that the experiences of psychological distress among an individual may diminish or disappear, while in the presence of interpersonal ties that offer social support and display same characteristics (Bos et al., 2008; Peplau \& Fingerhut, 2007). The sexual minority community represents, to some participants although not all, an element of identity tolerance and hope.

Identity tolerance.

Identity tolerance refers to the individual's ability to live with what they have identified about themselves despite the rejection (Cass, 1979). In this study, the participants have managed identity tolerance which is the third stage of identity formation as sexual minority group as it has helped them to lessen the feeling of isolation from the broader campus society.

\section{Conclusion}

The principal outcome of this study, which is also a new contribution to the field of research on this topic, is that the students foresee rejection and discrimination in their future as professionals due to their sexual orientation. The fear of not being accepted by their society, colleagues and those above them in their workplaces in the future leads to thinking of hiding their identity in order to get employment and move up in the hierarchy of their work and also to protect their loved ones. For example, their family members which leads to multiple identities. This phenomenon contributes to the participant's identity crisis that is leaving them more vulnerable to some chronic stressors. These stressors later affect the psychological well-being of participants. It is then that resilience becomes a concern. 
The emotional quality of the contact with other gay or lesbian people within the campus is the one that keeps the participants going as they realise they are not alone. Support from friends within the group seems to be beneficial to some of the individuals. These friends contribute positively to the well-being of each member of the group as they provide them with emotional support. From the accounts and analysis shown above, participants in this study have demonstrated a moderate level of resilience as they have shown two indicators of resilience; namely, a) friends as a source of resilience and $b$ ) the sexual minority community as a source of resilience. The individual participants have had positive contact with members of the gay and lesbian community on campus and are able to accept and integrate their sexual orientation with that of the group (Troiden, 1989). Unfortunately, family and society as supports were not reported by participants.

\section{Recommendations}

It has become clear that there is the need for support from healthcare providers; for example, student counsellors on campus can help enhance psychological wellbeing of homosexual students through education and a supportive attitude to the homosexual group. This will help individuals who struggle with prejudice and discrimination from families or other sources cope with everyday stress they encounter. This, in turn, may facilitate selfacceptance and psychological wellbeing. Further studies should contribute to the development of effective coping strategies and facilitate ways in which individuals can disclose their sexual orientation to increase possibilities of positive feedback.

\section{Practical recommendations}

- Facilitating homosexual students' adjustment in university settings would entail helping them to build a positive self-esteem which, in turn, could enable help in mastering their environment and improving their psychological wellbeing.

- Healthcare professionals should educate sexual minority students about the possible negative outcomes of using substances as a way of coping with discrimination and prejudice. Such education will also help prevent HIV transmission and better ways of less risky sexual patterns among MSM (Kerwin et al (20II)

- Professionals such as campus counsellors and nurses can facilitate group discussions, explore individual coping resources and nurture sexual minority confidence.

- Sensitivity training for staff members, particularly lecturers and professors who serve as authority figures for the students.

- Both quantitative and qualitative researches be done and carried out in this area of sexual minority.

\section{Limitations}

One major limitation identified in this study was the problem of getting students to participate. Initially they were scared to participate and eventually only II participants agreed to participate. This 
then necessitated the choice of design and research approach.

\section{Acknowledgement:}

The authors acknowledge, with thanks, the courage of the students who participated in the study.

\section{Competing Interests}

The authors do not have any financial or personal relationships to any organization that may have indirectly or directly influenced the writing of this article.

\section{Author's Contribution}

ESI conceptualized the study title and wrote the manuscript with subsequent revision; PK also contributed to part of the study conceptualization and wrote methodological section, while PT collected data. All authors provided literature.

\section{References}

Angen, M.J. 2000. Evaluating interpretive inquiry: Reviewing the validity debate and opening the dialogue. Qualitative Health Research, 10(3): 378-395. doi: I0.1 I 77/10497323000I 000308.

APA. 2008. Resilience in African-American children and adolescents: $A$ vision for optimal development. Washington, DC: American Psychological Association's Task Force on Resilience and Strength in Black Children and Adolescents.

Balsom, K.F. \& Mohr, J.J. 2007. Adaptation to sexual orientation a comparison of bisexual and lesbian/gay. Journal of Counselling Psychology, 54(3): 306319.
Baumann, A. \& Muijen, M. 20I0. Mental health and well-being at the workplace: Protection and inclusion in challenging times. Available from http://www.euro.who.int/data/assets/pdf-file 02.06.2013).

(Retrieved

Blumer, H. 1969. Symbolic Interactionism, perspectives and method. Englewood Cliffs, NJ:Prentice Hall.

Bos, H.M.W., Sandfort, T.G.M., Bruyn, E.H \& Hakvoort, E.M. 2008. Same-Sex attraction, social relationships, psychosocial functioning, and school performance in early adolescence. Developmental Psychology, 44(I): 5968.

Bowleg, L., Huang, J., Brooks, K., Black, A. \& Burkholder, G. 2003. Triple jeopardy and beyond: Multiple minority stress and resilience among Black lesbians. Journal of Lesbian Studies, 7, 87-I08.

Braun, V. \& Clarke, V. 2006. Using thematic analysis in psychology. Qualitative Research in Psychology, 3(2): 77-I0I.

Bridges, S.K., Selvidge, M.M.D., \& Matthews, C.R. 2003. Lesbian women of colour: Therapeutic issues and challenges. Journal of Multicultural Counselling and Development, 31: II3-130.

Brown, A. 2006. A narrative approach to collective identities. Journal of Management Studies, 43(4): 73I-753. doi: $10.1111 / \mathrm{j}$. 14676486.2006.00609.x

Broyden, J. \& Mann, G. 2005. Children's risk, resilience, and coping in extreme situations, pp. 3-26 In M. Ungar (Ed.), Handbook for working with children and youth: Pathways to resilience 
across cultures and contexts. Thousand Oaks, CA: Sage.

Casey, B.J., Tottenham, N., Liston, C. \& Durston, S. 2005. Imaging the developing brain: What have we learned about cognitive development? Trends in Cognitive Science, 9: 104IIO.

Cass, V.C. 1979. Homosexual identity formation: A theoretical model. Journal of Homosexuality, 4: 219-235.

Castro, F.G. \& Murray, K.E. 20I0. Cultural adaptation and resilience: controversies, issues and emerging models, pp. 375-403. In J.W. Reich, A.J. Zautra \& J.S. Hall (Eds.), Handbook of Adult Resilience. New York: Guilford Press.

Clandinin, D.J., \& Connelly, F.M. 2000. Narrative inquiry: Experience and story in qualitative research. San Fancisco: Josey-Bass.

Cole, J.B. \& Guy-Sheftall, B. 2003. Gender talk: The struggle for women's equality in African American communities. New York: Ballantine Publishing Group.

Compton, W.C. 2005. Introduction to positive psychology. Thomson/Wadsworth: University of Virginia.

Creswell, J.W. 2007. Qualitative inquiry and research design: Choosing among five approaches. (2nd ed.). London: SAGE.

Devos, T. \& Banaji, M.R. 2003. Implicit self and identity. In M.R. Leary., J.O. Tangney. (Eds.) Handbook of Self and Identity. Guilford: New York.

Dlamini, B. 2006. Homosexuality in the African context. Agenda, 20(67): |28-136.
Ellemers, N., Spears, R. \& Doosje, B. 2002. Self and Social Identity. Annual review of Psychology, 53: |6|-|86. doi: 10.1 |46/annurev.psych.53.10090I.135 228.

Finerty, C.E. 20I0. Being Gay in Kenya: The Implications of Kenya's new Constitution for its Anti-sodomy laws. Cornell International Law Journal, 45: 432-459.

Gibson, D.D., Schlosser, L.Z. \& BrockMurray, R.D. 2007. Identity management Strategies Among Lesbians of African- Ancestry: A Pilot study. Journal of LGBT Issues in Counseling, I (4): 3I-57.

Gilman, S.E., Cochran, S.D., Mays, V.M., Hughes, M., Ostrow, D., Kessler, R.C. 200I. Risk of Psychiatric disorders among individuals reporting same-sex sexual partners In the National comorbidity survey. American Journal of Public Health, 91 (6): 933-943.

Graziano, K. 2004. Coming out on a South African university campus: adaptations of gay men and lesbians. Society in Transition, 35(2): 273-286.

Greene, B. 2000. African American lesbian and bisexual women. Journal of Social Issues, 56: 239-249.

Hall, J.A. \& La France, B.H. 2007. Attitudes and communication of communicating homophobia in fraternities: Separating the impact of social adjustment function from hetero-identity concern. Journal of Communication Quarterly, 60(I): 35-58.

Herek, G.M., \& Garnets, L.D. 2007. Sexual orientation and mental health. Annual Review of Clinical Psychology, 3, 353375. 
Herndon, M.K. \& Hirt, J.B. 2004. Black students and their families: What leads to success in College. Journal of Black Studies, 34(4): 489-5। 3.

Idemudia, E.S. 2003. Culture, psychosocial disorders and mental health: An African perspective. Poster presented at the International Association for CrossCultural Psychology $6^{\text {th }}$ European Regional Congress, Budapest, Hungary. Idemudia, E.S. 2009. Cultural dynamics of Trauma Expression and Psychotherapy: The African Perspectives (Chapter 5). In S.N. Madu (Ed): Trauma and Psychotherapy in Africa (ISBN: 978-098|4I25-3-5) (Chapter 5). pp. 43-50. University of Limpopo (Turfloop Campus), Press, South Africa for the World Council for Psychotherapy (African Chapter)

Idemudia, E.S. 2010. Cultural factors of HIV/AIDS spread and prevention in Africa: A psychosocial perspective. Poster presented at the National AIDS/HIV conference, Abuja, Nigeria. Idemudia, E.S. \& Ndlovu, N.D. 20I3. How happy are married people? Psychological indicators of marital satisfaction of married men and women in Gauteng Province, South Africa. Gender \& Behaviour, II(2): 54865498. (ISSN-I596-923I).

Institute of Medicine. 20II. The health of lesbian, gay, bisexual, and transgender people: Building a foundation for better understanding. DC: The National Academies Press Washington. Jamil, O.B. 20I0. I am the melting pot: Multiple Identity Integration among gay/ bisexual/questioning male ethnic minority adolescents. Theses and
Dissertation, University Libraries: DePaul University.

Jones, S.R. \& McEwen, M.K. 2000. A conceptual Model of Multiple Dimensions of Identity. Journal of College Student Development, 4I(4): 405-4|4.

Kerwin, J.T., Foley, S.M., Thornton, R.L., Basinga, P. \& Chinkhumba, J. $201 \mathrm{l}$. Missing safer sex strategies in HIV population: A call for further research. African Population Studies, 25 (2), 286297.

King, M., McKeown, E., Warner, J., Ramsay, A., Johnson, K., Cort, C., Wright, I., Blizard, R., \& Davidson, O. 2003. Mental health and Quality of life of gay and lesbians in England and Wales: controlled cross-sectional study. British Journal of Psychiatry, 183: 552558.

King, M., Semlyen, J., Tai, S.S., Killaspy, H., Osborn, D., Popelyuk, D. \& Nazareth, I. 2007. Mental disorders, suicide and deliberate self-harm in lesbian, gay and bisexual people: A systematic review. London: National Institute for Mental Health in England.

Langhinrichsen-Rohling, J., Lamis, D.A. \& Malone, P. 20II. Sexual attraction status and adolescent suicide proneness: The roles of hopelessness depression and social support. Journal of Homosexual, 58(5): 52-82.

Lock, J. \& Steiner, H. 1999. Gay, Lesbian and Bisexual youth risks for emotional, physical and Social Problems: results from community- based survey. Journal of the American Academy of Child and Adolescent Psychiatry, 38: 297-304. 
Maree, K. (Ed.) 2007. First steps in research. Pretoria, South Africa: Van Schaik.

Matthew, V., Douglas, A. \& MacDonald. 2012. A. Personality and Individual Differences. An Examination of the factorial dimensionality of the Marlowe Crowne Social Desirability Scale, 52: 487-49l.

Mayock, P., Bryan, A., Carr, N. \& Kitching, K. 2009. Supporting LGBT Lives: A study of the mental health and wellbeing of lesbian, gay, bisexual and transgender people. New York: USA.

Mays, V.M. \& Cochran, S.D. 2000. Mental health correlates perceived discrimination among lesbian, gay and bisexual adults in the United States. American Journal of Public Health, 91: 1869-1876.

McLean, C.A. \& Campbell, C.M. 2003. Locating research informants in a multiethnic community: Ethnic identities, social networks and recruitment methods. Ethnicity \& Health, 8(I): 4I61.

Meyer, I.H. 2003. Prejudice, social stress, and mental health in lesbian, gay, and bisexual populations: conceptual issues and research evidence. Psychological Bulletin, I29(5), 674-607.

Miles, J.R. \& Kivlighan, D.M., Jr. 2012. Perceptions of group climate by social identity group in intergroup dialogue. Group Dynamics: Theory, Research, and Practice, 16(3): 189-205. doi: I0.1037/a0028634.

Momtaz, Y., Hamid, Ibrahim, R., Yahaya, N. \& Chai, S. 20I I. Moderating effect of religiosity on the relationship between social isolation and psychological wellbeing. Mental Health, Religion \&
Culture, 14(2): 14-156. doi: | 0. I080/ I 3674676.20| 0.497963

Noy, C. (2008). Sampling knowledge: the Hermeneutics of snowball sampling in qualitative

research. International Journal of social Research Methodology I I(4), 327- 344 doi:

http://dx.doi.org// 0. I 080// 364557070 I407305

Patton, L.D. \& Simmons, S.L. 2008. Exploring complexities of multiple Identities of Lesbians in Black College Environment. Negro Educational Review, 59: 3-4.

Peplau, A.L. \& Fingerhut, A.W. 2007. The close relationships of lesbians and gay men. Annual Review of Psychology, 58(10): 10-20.

Perales, F. 2015. The costs of being "different": Sexual identity and subjective wellbeing over the life course. Social Indicators Research. doi |0.|007/s | | 205-0| 5-0974.

Polit, D.F. \& Beck, C.T. 20I0. Essentials of nursing research: Appraising Evidence for Nursing Practice. Florida State University: USA.

Reed, T. 2013. Uganda parliament closes closet door on kill the gays bill. PQ monthly (Retrieved 8 May 2013).

Rhoads, R.A.W. 1997. Understanding Governance: Policy networks, Governance, Reflexivity and Accountability. Buckingham: Open University Press.

Robinson, K.H., Bansel, P., Denson, N., Ovenden, G. \& Davies, C. 2014. Growing up queer: Issues facing young Australians who are gender variant and sexuality diverse. Melbourne: Young 
and Well Cooperative Research Centre.

Rostosky, S.S., Riggle, E.D.B., Gray, B.E. \& Hatton, R.L. 2007. Minority stress experiences in committed same-sex couple relationships. Professional Psychology: Research and Practice, 38(4): 392-400. doi: 10.1037/07357028.38.4.392.

Ryff, C.D. 1989. Happiness is everything, or is it? Explorations on the meaning of psychological well-being. Journal of Personality and Social Psychology, 55(6): 1069-1089.

Schmidt, C.K., Miles, J.R. \& Welsh, A.C. 20II. Perceived discrimination and social support: The influences of career development and college adjustment of lesbian college students. Journal of Career Development, 38(4): 293-309.

Smuth, L. 20I I. Coming out as a lesbian in Johannesburg South Africa: considering interesting identities and social spaces. Journal of South African Review of Sociology, 42(3): 23-40.

Stewart, A.J. 2000. Challenges faced by Homeless Sexual minorities: Comparison of Gay, Lesbian, Bisexual, and Transgender Homeless Adolescents with Their Heterosexual Counterparts. American Journal of Public Health, 92(5): 773-777.

Traseen, B., Martinussen, M., Vitterso, J. \& Saini, S. 2009. Sexual orientation and quality of life among University students from Cuba, Norway, India and South Africa. Journal of Homosexuality, 56(I): 655-669.

Troiden, R.R. 1989. The formation of homosexual identities. Journal of Homosexuality, I7: 43-73.

Uhrig, S.C.N. 2015 (forthcoming). Sexual orientation and poverty in the UK: A review and top-line findings from the UK household longitudinal study. Journal of Research in Gender Studies.

Ungar, M. 2004. Nurturing hidden resilience in troubled youth. Toronto: University of Toronto Press.

Whitley, B.E. 20II. Gender- role variables and attitudes toward homosexuality. Sex Roles, 45: 69I-70I.

Yoshino, K. 2006. Covering: The hidden assault on our civil rights. New York: Randon House. 